\title{
Effect of different pasteurisation temperature on physicochemical properties, bioactive compounds, antioxidant activity and microbiological qualities of reconstituted pomegranate juice (RPJ)
}

\author{
${ }^{1}$ Kong, T.Y., ${ }^{1 *}$ Hasnan, N.Z.N., ${ }^{2}$ Nur Diyana, A., ${ }^{3}$ Nurin-Zulkifli, I.M., ${ }^{1}$ Basha, R.K., \\ ${ }^{1}$ Abdul Ghani, N.H. and ${ }^{1}$ Aziz, N.A. \\ ${ }^{1}$ Department of Process and Food Engineering, Faculty of Engineering, Universiti Putra Malaysia, 43400 \\ Serdang, Selangor, Malaysia. \\ ${ }^{2}$ Food Science and Technology Research Centre, Malaysian Agricultural Research and Development \\ Institute, 43400 Serdang, Selangor, Malaysia. \\ ${ }^{3}$ Agrobiodiversity and Environment Research Centre, Malaysian Agricultural Research and Development \\ Institute, 43400 Serdang, Selangor, Malaysia.
}

\begin{abstract}
Article history:
Received: 3 September 2020

Received in revised form: 13 October 2020

Accepted: 29 December 2020

Available Online: 31

December 2020

Keywords:

High-temperature

pasteurisation (HTP),

Mild-temperature

pasteurisation (MTP),

Physicochemical properties,

Reconstituted pomegranate

juice,

Anthocyanin,

Microbial inactivation
\end{abstract}

DOI:

https://doi.org/10.26656/fr.2017.4(S6).057

\begin{abstract}
Reconstituted pomegranate juice (RPJ) was thermally treated with high-temperature pasteurisation (HTP) at $95^{\circ} \mathrm{C}$ and mild-temperature pasteurisation (MTP) at $80^{\circ} \mathrm{C}$ for $30 \mathrm{~s}$ respectively. As a comparison, the effect on physicochemical properties, including antioxidant activities and microbial inactivation was eavluated. Both MTP and HTP showed effective inactivation of microbial growth to negligible level with MTP taking almost half pasteurisation-time $(-46.3 \%)$ as compared to HTP, indicating possible less energy usage. MTP and HTP treatment delivered insignificant difference in $\mathrm{pH}$, titratable acidity, total soluble solids and colour changes $(\Delta \mathrm{E})$ based on Commission Internationale de l'Elcairage (CIE) colour system. A significantly higher CIE $a$ values and reduction in $L$ and $b$ were obtained for MTP-juice indicating an increase in red tonalities due to increase in anthocyanin contents. As for antioxidant activity and extractability of bioactive compound, interestingly HTP delivered better results due to more phenols and anthocyanin were released during the heating, leading to further release of initially membrane-bound phenols. These findings suggested that both HTP and MTP are able to meet the microbiological safety and comparable physicochemical qualities. Nonetheless, HTP has shown higher functional values due to higher extractability of antioxidant compounds.
\end{abstract}

\section{Introduction}

Pomegranate juice $(\mathrm{PJ})$ is antioxidant-rich with high contents of polyphenols. Being native to Iran and Afghanistan, the cultivation of the pomegranate fruit, Punica granatum L., has nowadays spread to Tunisia, Turkey, Morocco, Spain, Pakistan, Saudi Arabia and subtropical regions of South America (Yahia, 2017). The consumption of its fresh juice is popular in those regions due to its notable antioxidant property and the potential health-promoting benefits (Karimi et al., 2017). The high antioxidant activity of the juice is believed to protect humans against the oxidative stress and reduce, subsequently, the risk of chronic diseases as well as to prevent disease development such as cancer, cardiovascular diseases, neurodegeneration and autoimmune disorder (Zaouay et al., 2017). Anthocyanins, an antioxidant that is profoundly available in pomegranate arils, are responsible for the red colour of pomegranate juices and proven to inhibit lipid peroxidation that can damage cells (Karimi et al., 2017). It was reported by Alighourchi et al. (2013) and Boggia et al. (2013) that the consumption of pomegranate juice nowadays is not only intense around its cultivar provinces but has spread to other regions crossing the international borders of non -cultivar countries. In those regions where the fresh fruits are rarely available, the ready-to-drink (RTD) juice can be found in form of reconstituted pomegranate juice (RPJ). The reconstituted juice is a juice manufactured from the fruit juice concentrate. While the price of RPJ may be expensive in non-cultivar countries, its market growth has shown encouraging progress due to the rising awareness of consumers on the health-promoting and antioxidant features of pomegranate (Boggia et al., 2013; 
Rinaldi et al., 2013).

Several studies have reported on noticeable quality changes throughout the different stages of the RPJ manufacturing such as astringency, flavour and colour when compared to the Fresh PJ (FPJ) (Davarci et al., 2019). Inevitably, RPJ do not offer as high nutritional qualities as of the freshly squeezed juice. It is, however, important for the industry to appreciate the fact that the consumer's purchasing motivation for the RPJ is mostly due to its antioxidants-rich property especially in the non -cultivar countries, despite its expensive price. Thus, minimizing the degradation of its quality and nutritional values is valuable from the point of view of consumer's health and responsibility that need to be undertaken by the manufacturers through the appropriate manufacturing techniques.

In general, thermal pasteurisation is an established practice among fruit juice manufacturers and bottlers, whereby the RPJ is commonly pasteurized twice before reaching the consumer. The first or primary pasteurisation $\left(95-98^{\circ} \mathrm{C}, 30 \mathrm{~s}\right)$ takes place during the production of concentrate, extracted from the fresh fruits, whereby the purpose was to inactivate enzymes from the fruit (Andersson et al., 2016). Microorganisms are also inactivated during this pasteurization. After the concentrated is produced in the range of $65-70{ }^{\circ} \mathrm{Brix}$, it is then transported to the secondary manufacturers. At the secondary factories, the juice can be reconstituted by diluting the concentrate to the targeted values of Brix as outlined by the regulation or the requirement in the region where the juice is sold. The resulted RPJ is required to undergo secondary pasteurization to reduce possible recontamination risk during the manufacturing stages and then, aseptically packed in various types of packaging material depending on the manufacturers (Vegara et al., 2013). Typical secondary pasteurisation in the industry is specified often as $95^{\circ} \mathrm{C}$ for $30 \mathrm{~s}$ (Kaavya et al., 2019), followed by cooling process. Nevertheless, such pasteurization practice was found to cause excessive microbial lethality that resulted in unnecessary quality degradation and nutritional loss as well as browning since the first pasteurisation has been carried out at a high temperature. Milder heat treatment at $\leq 80^{\circ} \mathrm{C}$ was comparatively claimed to capable preserving the juice from microbial activity while retaining the quality as well as nutritional values with less energy usage as discussed by Andersson et al. (2016) for the orange juice. Among the key qualities that dictate the values of the juice are the physicochemical properties especially the colour and the antioxidant activity as well as total phenol and anthocyanin content.

Regardless, the potential benefits that can be obtained at milder heat treatment $\left(\leq 80^{\circ} \mathrm{C}\right)$ as compared to high-temperature pasteurisation $\left(95^{\circ} \mathrm{C}, 30 \mathrm{~s}\right)$, there is little information on their effect comparison for the reconstituted juice, especially the RPJ. Therefore, the objective of this study was to compare the effectiveness of mild-temperature pasteurisation (MTP) and hightemperature pasteurisation (HTP) in preventing microbial growth while retaining the physicochemical properties as well as the nutritional values (antioxidant activity, total phenol and anthocyanin content). Importantly, yeast and mould count as well as standard plate count (SPC) were evaluated to determine the effectiveness of both MTP and HTP. As a note, the study on the changes during the storage period was excluded in this paper and only focused on the changes at the point after the pasteurisation process.

\section{Materials and methods}

\subsection{Preparation of reconstituted pomegranate juice} (RPJ)

RPJ was prepared by diluting the pomegranate concentrate with chilled water $\left(3^{\circ} \mathrm{C}\right)$, treated using reverse osmosis process based on the ratio provided by the juice manufacturer. No preservative or added sugar were added in line with the proposal to prepare healthy juice. A total of three samples were prepared, whereby one sample was not pasteurised and used as control, while the remaining two samples were proceeded for high-temperature pasteurisation (HTP) and mildtemperature pasteurisation (MTP)

\subsection{Pasteurisation of RPJ}

Pasteurisation of RPJ was performed at both HTP and MTP conditions. Based on HTP $\left(95^{\circ} \mathrm{C}, 30 \mathrm{~s}\right)$, the 200 $\mathrm{mL}$ RPJ was poured into a pre-sterilized stainless steel container and heated until the temperature reached $95^{\circ} \mathrm{C}$ and hold for $30 \mathrm{~s}$ in a laboratory-scale pasteurization system. The pasteurized juice was then rapidly cooled and bottled in polyethylene terephthalate (PET) bottles. As for the MTP $\left(80^{\circ} \mathrm{C}, 30 \mathrm{~s}\right)$, the experimental work was repeated by heating the RPJ up to $80^{\circ} \mathrm{C}$ and hold for 30 s. Both samples were analysed for physicochemical, microbiological and antioxidant properties.

\subsection{Microbial inactivation analysis}

Colony forming units (CFU) were determined by standard spread-plate methodologies. Decimal dilutions from unpasteurised, HTP- and MTP-juice were made in buffered peptone water and then $0.1 \mathrm{~mL}$ of appropriate dilutions were plated in duplicate for standard plate counts (SPC) on standard plate count agar. For yeast and mould counts (YMC), $0.1 \mathrm{~mL}$ of appropriate dilutions 
were plated on Sabouraud dextrose chloramphenicol agar. Inactivation of microorganisms by thermal treatment was determined by total SPCs and YMC. The colonies were counted by using a standard plate count method to quantify the colony forming units per $\mathrm{mL}$ $(\mathrm{CFU} / \mathrm{mL})$.

\section{$2.4 \mathrm{pH}$ measurement}

The juice $\mathrm{pH}$ was determined by using $\mathrm{pH}$ meter $(\mathrm{pH}$ -600 , Milwaukee, Romania) at room temperature of $24 \pm 2^{\circ} \mathrm{C}$. The meter was first calibrated with distilled water at $\mathrm{pH}$ of 7.0. Samples of unpasteurised and pasteurised RPJ were placed in a beaker for $\mathrm{pH}$ measurement.

\subsection{Total soluble solid (TSS)}

TSS of RPJ was measured on Brix value by using a digital refractometer (PAL-1, Atago, Japan). The instrument was first calibrated using distilled water by placing a few drops of distilled water on the digital refractometer prior to the test. Then, a substantial amount of RPJ was dropped onto the refractometer and the resultant reading on the digital refractometer refer to the reading of TSS of the RPJ samples.

\subsection{Titratable acidity (TA)}

Approximately, $5 \mathrm{~mL}$ of unpasteurised and pasteurised RPJ samples were diluted to $20 \mathrm{~mL}$ of distilled water and was titrated against $0.1 \mathrm{M} \mathrm{NaOH}$ to a pink endpoint using phenolphthalein indicator. Total titratable acidity $(T A)$ was calculated using the following formula:

$$
T A\left(\% \frac{w t}{v o l}\right)=\frac{N \times V_{1} \times E q \cdot W_{1}}{V_{2} \times 10}
$$

Where $N=$ normality of $\mathrm{NaOH}, V_{l}=$ volume of $\mathrm{NaOH}$ $(\mathrm{mL}), V_{2}=$ volume of sample $(\mathrm{mL})$ and $E q . W t=$ equivalent weight of predominant acid, citric acid.

\subsection{Colour measurement}

A colourimeter (D65, HunterLab, USA) was used for colour measurements. The instrument was calibrated with a white standard tile. A glass beaker containing the samples was placed below the light source. Colour data were measured based on CIELAB colour characterization system as defined by the Commission Internationale de l'Eclairage (CIE). CIE L* for lightness, $\mathrm{a}^{*}$ for redness, and $\mathrm{b}^{*}$ for yellowness were measured. Chroma $\left(C^{*}\right)$, hue angle $\left(h^{\circ}\right)$ and colour difference were calculated as follows:

Chroma, $C^{*}=\left(a^{*^{2}}+b^{*^{2}}\right)^{1 / 2}$

Hue angle, $h^{\circ}=\arctan b * / a *$

Colour difference, $\Delta E$, $=\left(\Delta L^{*^{2}}+\Delta a^{*^{2}}+\Delta b^{*^{2}}\right)^{1 / 2}$

\subsection{Quantification of total phenolic contents (TPC)}

Procedure for the determination of TPC was adapted and modified from Johari and Khong (2019). The sample was prepared by liquefying $10 \mathrm{mg}$ of the RPJ in $100 \mathrm{~mL}$ of the ethanol to yield a concentration of $100 \mu \mathrm{g} / \mathrm{mL}$. Approximately, $0.5 \mathrm{~mL}$ of the RPJ sample $(100 \mu \mathrm{g} / \mathrm{mL})$ was mixed with $2 \mathrm{~mL}$ of the Folin Ciocalteu's reagent and was neutralised with $4 \mathrm{~mL}$ of $20 \%$ sodium carbonate solution. The reaction mixture was incubated at room temperature for 30 minutes or until a blue colour was developed. The absorbance of the RPJ sample was measured at $750 \mathrm{~nm}$ using UV spectrophotometer (Cary 50, Varian, Netherland). The total phenolic contents were determined from the linear equation of a standard curve prepared with gallic acid. The content of total phenolic compounds was expressed as gallic acid equivalent (GAE).

\subsection{Quantification of total anthocyanin}

Procedure for determination of anthocyanin content was adapted and modified from Mayuoni Kirshenbaum et al. (2016) using UV spectrophotometer (Cary 50, Varian, Netherland). $5 \mathrm{~mL}$ RPJ sample were added to 95 $\mathrm{mL}$ of $0.025 \mathrm{~mol} / \mathrm{L}(0.025 \mathrm{M})$ potassium chloride at $\mathrm{pH}$ 1.0 and $0.4 \mathrm{~mol} / \mathrm{L}(0.4 \mathrm{M})$ sodium acetate at $\mathrm{pH} 4.5$. The sample was incubated for $15 \mathrm{~min}$ at room temperature and absorbance at 510 and $700 \mathrm{~nm}$ was measured with an UV spectrophotometer. The absorbance, $A$, was calculated as:

The monomeric anthocyanin pigment concentration was calculated as cyanidin-3-glucoside equivalent according to the following equation:

$A=\left(A_{510} \mathrm{~nm}-A_{700} \mathrm{~nm}\right){ }_{\mathrm{pH} 1.0}-\left(A_{510} \mathrm{~nm}-A_{700} \mathrm{~nm}\right)$ $\mathrm{pH} 4.5$

Where $A=$ absorbance, $M W=$ molecular weight (449.2 $\mathrm{g} / \mathrm{mol}), D F=$ dilution factor, $\varepsilon=$ molecular absorptivity $(26,900 \mathrm{~L} / \mathrm{cm}-\mathrm{mol}), L=$ path length $(\mathrm{cm})$

Total concentration $(\mathrm{mg} / \mathrm{L})=A \times M W \times D F \times$ $1000 /(\varepsilon \times L)$

\subsection{Antioxidant activity (AOX) based on DPPH-radical scavenging assay and FRAP-method}

The procedure for determining antioxidant activity using DPPH-method was adapted and modified from Siatka and Kašparová (2010) based on the basis of the scavenging activity of the stable DPPH free radical. In brief, $1 \mathrm{~mL}$ of the diluted sample was added to $2.850 \mathrm{~mL}$ of DPPH working solution. After $30 \mathrm{~min}$ incubation, absorbance was measured at $515 \mathrm{~nm}$ using UV spectrophotometer (Cary 50, Varian, Netherland). The antioxidant activity was determined from the linear equation of a standard curve prepared with ascorbic acid. 
The antioxidant activity was expressed as ascorbic acid equivalent (AAE) and was later multiplied with the dilution factor.

Total concentration $(\mathrm{mgAAE} / \mathrm{L})=[(A-c) / m] \times \mathrm{DF}$

Where $A=$ absorbance, $c=\mathrm{y}$-intercept on standard curve of ascorbic acid, $m=$ gradient of standard curve of ascorbic acid and $D F=$ dilution factor

The procedure for determining antioxidant activity using FRAP-method was adapted and modified from Martins et al. (2013). Briefly, the FRAP reagent was prepared by mixing acetate buffer $(150 \mathrm{~mL}, \mathrm{pH} 3.6)$, $\mathrm{FeCl}_{3}$ solution $(15 \mathrm{~mL})$ and a solution of $0.0625 \mathrm{~g}$ of $4,6-$ tripryridyl-s-triazine (TPTZ) powder that was dissolved in $20 \mathrm{~mL}$ of $40 \mathrm{mM}$ hydrochloric acid. This FRAP working solution was later shaken in a water bath at $37^{\circ} \mathrm{C}$. The FRAP solution $(2.85 \mathrm{~mL})$ and sample solutions $(1 \mathrm{~mL})$ were added to each well and mixed thoroughly. The absorbance was taken at $593 \mathrm{~nm}$ after 30 min incubation. The antioxidant activity was determined from the linear equation of a standard curve prepared with ascorbic acid. The antioxidant activity was expressed as ascorbic acid equivalent (AAE) and later multiplied with the dilution factor as in Equation 6.

\subsection{Statistical analysis}

Collected data were analysed by using Minitab 19.0 software. Each analysis was implemented in triplicate and data were represented as a mean value \pm standard deviation $(\mathrm{n}=3)$ as well as analysed using analysis of variance (one-way ANOVA) with Tukey's test at a significance level of $p<0.05$. Pearson's correlation test was carried out to identify the correlation between antioxidant activities with total phenolic content.

\section{Results and discussion}

\subsection{Microbial inactivation analysis}

The unpasteurised RPJ was found to have only 10 $\mathrm{CFU} / \mathrm{mL}$ for both SPC and YMC due to its nature of being reconstituted juice produced from readily pasteurised concentrate. Additionally, the reconstitution step in this study was carried out in laminar flow hood and strict aseptic technique. After the pasteurisation step of the reconstituted juice, it was found that MTP- and HTP-samples have resulted in nil microbial count for SPC as well as YMC $(<1 \mathrm{CFU})$, which suggested that they were successfully inactivated below detection level. This proved that both MTP and HTP were effective to meet the food safety requirement for juice. As for the HTP, it took 49.85 1.02 min to complete while the MTP took less time $(-46.3 \%)$ to complete the pasteurisation for the $200 \mathrm{~mL}$ sample $(26.78 \pm 1.08 \mathrm{~min})$, which implied certainly higher energy usage that may actually unnecessary for the juice reconstitution industries. Nevertheless, it is important to note that spores of some bacteria and yeast may have survived during pasteurization process. Therefore a further study is recommended on the shelf-life investigation for both pasteurised samples during storage at the controlled condition.

\subsection{Physicochemical analysis ( $p H, T S S, T A$ and colour)}

The effect of both MTP and HTP on physicochemical properties of the RPJ is shown in Table 1 , which include $\mathrm{pH}$, TA, TSS and colour. Changes in the characteristics between the unpasteurised juice and the pasteurised juice are important since they determine the quality of juice as affected by the different heat load. The $\mathrm{pH}$ of unpasteurised juice, HTP- and MTP-juice were $3.53,3.17$ and 3.20 respectively. This shows a significant reduction in $\mathrm{pH}$ after the pasteurisation process $(\mathrm{pH}<0.05)$ even though there were no significant difference between the HTP- and MTP-juice ( $p>0.05)$. All $\mathrm{pH}$ values still lied within the range of standards desirable $\mathrm{pH}$ for pomegranate juice (Cam et al., 2009). The decrease in $\mathrm{pH}$ of pasteurised RPJ was due to the dissociation of citric acid since this acid is predominant in pomegranate fruit. It is important to control the $\mathrm{pH}$ of juice in the juice processing to be $<4.5$ as to limit the majority of the pathogenic microorganisms' growth (Kechero et al., 2019). In general, before the pasteurisation process, the RPJ samples are susceptible on recontamination and deterioration action of bacteria due to high water content as compared to its initial concentrated form $\left(72^{\circ}\right.$ Brix $)$ as well as the suitability of juice as substrates or environments for specialized pathogenic microorganisms. When the samples were pasteurised, majority of the vegetative forms of microorganisms were eliminated (not detected in microbial analysis). Nevertheless, dormant forms (spores) of some bacteria and yeast may have resisted the pasteurization and wait for a favourable environment for germination and growth even at low $\mathrm{pH}$ of the samples. Bacteria species reported with processed fruit juices although with $\mathrm{pH}<4.5$ include Bacillus, Clostridium, Lactobacillus, Leuconostoc and recently Alicyclobacillus spp. have been considered as target organisms for juice's quality evaluation due to recurrent linkage with contamination of acidic fruit juice, soft drinks and isotonic drinks (Batra et al., 2018). Hence, it is deduced that further studies on the rate of microbial growth of the treated samples during storage should be conducted to provide insight into requirement for filling and packaging process as well as storage parameters that can extend the shelf-life of juice without preservatives.

Organic acids content is an important figure for fruit juice as they influence the organoleptic properties 
(flavour, colour, and aroma), stability and microbiological control of the juice, whereby this is determined by titratable acidity (TA). The result shows that both HTP- and MTP did not significantly change the TA percentages $(\mathrm{p}>0.05)$ when compared to unpasteurised juice $(1.83 \%$ and $1.84 \%$ respectively). These values of TA agreed as studied by Cam et al. (2009) that reported the range of TA is between 0.22 to $3.17 \%$ in $100 \mathrm{~mL}$ juice. The predominant content of organic acid in pomegranate juice is citric acid for most cultivar, whereas it contributes to the flavour and sourness taste as well as determine the freshness of the juice.

Table 1. Effect of HTP and MTP on physicochemical properties of reconstituted pomegranate juice

\begin{tabular}{cccc}
\hline \multirow{2}{*}{ Properties } & Unpasteurised & HTP & MTP \\
\cline { 2 - 4 } & & $\left(95^{\circ} C, 30 \mathrm{~s}\right)$ & $\left(80^{\circ} \mathrm{C}, 30 \mathrm{~s}\right)$ \\
\hline pH & $3.53 \pm 0.02^{\mathrm{a}}$ & $3.17 \pm 0.05^{\mathrm{b}}$ & $3.20 \pm 0.05^{\mathrm{b}}$ \\
TSS $\left({ }^{\circ} \mathrm{Bx}\right)$ & $16.0 \pm 0.0^{\mathrm{a}}$ & $23.0 \pm 0.0^{\mathrm{b}}$ & $22.3 \pm 0.6^{\mathrm{b}}$ \\
TA $(\%)$ & $1.83 \pm 0.01^{\mathrm{a}}$ & $1.83 \pm 0.01^{\mathrm{a}}$ & $1.84 \pm 0.01^{\mathrm{a}}$ \\
CIE $L$ & $24.32 \pm 0.07^{\mathrm{a}}$ & $24.24 \pm 0.03^{\mathrm{a}}$ & $24.12 \pm 0.02^{\mathrm{b}}$ \\
CIE $a$ & $0.09 \pm 0.07^{\mathrm{a}}$ & $0.14 \pm 0.05^{\mathrm{a}}$ & $0.36 \pm 0.11^{\mathrm{b}}$ \\
CIE $b$ & $-0.75 \pm 0.35^{\mathrm{a}}$ & $-0.91 \pm 0.17^{\mathrm{a}}$ & $-1.15 \pm 0.14^{\mathrm{a}}$ \\
Hue angle $\left({ }^{\circ}\right)$ & $-78.59 \pm 2.91^{\mathrm{a}}$ & $-80.83 \pm 4.43^{\mathrm{a}}$ & $-72.57 \pm 5.42^{\mathrm{a}}$ \\
Chroma & $0.76 \pm 0.35^{\mathrm{a}}$ & $1.21 \pm 0.14^{\mathrm{a}}$ & $0.92 \pm 0.16^{\mathrm{a}}$ \\
$\Delta \mathrm{E}$ & - & $0.19 \pm 0.13$ & $0.42 \pm 0.24$ \\
\hline
\end{tabular}

*Values followed by the same letter within the same row are not significantly different from each other $(p>0.05)$. All values are reported as mean \pm standard deviation.

The total soluble solids (TSS) of both MTP- and HTP-juices were significantly higher, which is recorded at 22.3 and $23.0^{\circ}$ Brix respectively as compared to unpasteurised samples $\left(16.0^{\circ} \mathrm{Brix}\right)$. This result complied with the minimum Brix requirement as outlined by Codex general standard for fruit juices and nectars (CODEX STAN 247-2005) (FAO/WHO Food Standards, 2005). The thermal treatment has increased the TSS of juice which due to evaporation of water during heating and as a result of hydrolysis of polysaccharides into sugars.

Colour changes is an important quality for attracting consumers as they are associated with the freshness and the authenticity of the juices. The overall colour change $(\Delta \mathrm{E})$ after the pasteurisation processed was determined to classify whether the colour change is noticeable. The colour change for both pasteurised samples were less than 0.5 and this change could not be noticed by human eye as discussed by Murillo et al. (2019). Therefore, both MTP and HTP did not have significant difference in the colour when compared to unpasteurised juice. As expected, increase in CIE $a$ and reduction in CIE $b$ values were observed in both pasteurised samples with the highest increase of threefold rise in CIE $a$ for the MTP-sample while the increase in $+56 \%$ for the HTPsample. The increase in CIE $a$ values implied the rising intensity of reddish tonalities in the juice. Changes in CIE $L$ in decreasing trend was significantly associated with changes in CIE $a(\mathrm{p}<0.05)$, whereby CIE $L$ that range from 0 (black) to 100 (white) measures the lightness of the juice (Mohd-Hanif et al., 2016). As for hue angle and chroma, statistically significant differences were not found for pasteurised and unpasteurised samples.

\subsection{Effect on TPC}

ANOVA for TPC showed that the effect of both HTP and MTP was not significant $(p>0.05)$, in agreement with that obtained by Mena et al. (2013) whereby reported on the insignificant effect of thermal treatment on total phenols. Yet, minor increase of TPC among both pasteurised juices were observed in Table 2 , with the highest rise (+9.24\%) in HTP while $+0.81 \%$ in MTP as compared to the non-treated sample. Although initially it was perceived that thermal processing has a detrimental effect on the retention of the phenols, yet many studies include Sharma et al. (2015) and Colantuono et al. (2018) have observed rise in TPC after heating depending on the temperature and method. The heating may disrupt the cell membrane, leading to the release of membrane-bound phenols, which may result in an increase in bioavailability (Minatel et al., 2017). Nevertheless, heating at high temperature $\left(>100^{\circ} \mathrm{C}\right)$ will eventually decrease the phenol contents. In some cases, the inactivation of polyphenol oxidase (PPO) and peroxidase (POD), which are involved in the oxidation of phenolic compounds, can be obtained at $80^{\circ} \mathrm{C}$. Their inactivation, in turn, may reduce the oxidation activity of the phenols and maximises its recovery. It is, however, important to be noted, that the action of PPO and POD enzymes may not be applicable for this rise, because these enzymes are not active anymore since the juice has been thermally pasteurised during the production of original concentrate.

\subsection{Effect on total anthocyanins contents}

The results obtained for total anthocyanin content displayed statistically insignificant differences $(p=0.469)$ between unpasteurised and pasteurised juices with values ranging from 0.08 to $0.13 \mathrm{mg} / \mathrm{L}$ (Table 2). The lowest value was recorded for the unpasteurised juice, while the highest amount of these pigments was in the HTPsample, indicating that an increase in anthocyanin content when treated with thermal pasteurisation. This is in accordance with results obtained by Mena et al. (2013). In fact, an increase in the total anthocyanin 
Table 2. Effect of MTP and HTP on total phenolic content (mgGAE/L), total anthocyanin (mg/L) and antioxidant capacity of $\mathrm{RPJ}$ (mgAAE/L) as measured by different methods

\begin{tabular}{lcccc}
\hline Treatment & TPC (mgGAE/L) & $\begin{array}{c}\text { Total anthocyanin } \\
(\mathrm{mg} / \mathrm{L})\end{array}$ & $\begin{array}{c}\text { Antioxidant activity based Antioxidant activity based } \\
\text { on FRAP-method } \\
(\text { mgAAE/L) }\end{array}$ & $\begin{array}{c}\text { on DPPH-method } \\
(\text { mgAAE/L) }\end{array}$ \\
\hline $\begin{array}{l}\text { None } \\
\text { HTP }\end{array}$ & $1353 \pm 90^{\mathrm{a}}$ & $0.05 \pm 0.01^{\mathrm{a}}$ & $30.03 \pm 1.69^{\mathrm{b}}$ & $958.30 \pm 76.26^{\mathrm{a}}$ \\
$\left(95^{\circ} \mathrm{C}, 30 \mathrm{~s}\right)$ & $1478 \pm 25^{\mathrm{a}}$ & $0.13 \pm 0.02^{\mathrm{a}}$ & $40.17 \pm 2.13^{\mathrm{a}}$ & $1024.35 \pm 52.62^{\mathrm{a}}$ \\
$\mathrm{MTP}$ & & & & \\
$\left(80^{\circ} \mathrm{C}, 30 \mathrm{~s}\right)$ & $1364 \pm 17^{\mathrm{a}}$ & $0.08 \pm 0.02^{\mathrm{a}}$ & $36.41 \pm 1.93^{\mathrm{a}}$ & $1026.16 \pm 6.93^{\mathrm{a}}$ \\
\hline
\end{tabular}

*Values followed by the same letter within the same column are not significantly different from each other ( $p>0.05)$. All values are reported as mean \pm standard deviation.

contents correlated very well with the increase of TPC $(r=0.729)$. This was due to the conversion of colourless leucoanthocyanins into red anthocyanin when heated in acidic condition. This was confirmed with the increasing CIE $a$ value and decreasing $b$ value in both pasteurised samples as compared to unpasteurised samples, indicating the increasing red colour when anthocyanin content increased. This is hence, seen as a positive effect since the intense red colour of pomegranate juice is perceived as attractive to consumers (Mayuoni Kirschenbaum et al., 2016)

\subsection{Effect on antioxidant activity (AOX)}

Results of AOX measured by FRAP and DPPH assay are shown in Table 2 . The AOX capacity measured by FRAP assay was significantly influenced by the thermal pasteurisation. The highest value was found for the HTP-sample $(40.17 \pm 2.13 \mathrm{mgAAE} / \mathrm{L})$ with an increase of $+34 \%$ while for the MTP, an increase of $+21 \%$ in $\mathrm{AOX}$ to $36.41 \pm 1.93$ was recorded when compared with unpasteurised juice. Meanwhile, the AOX capacity measured by DPPH assay was also significantly influenced by the thermal pasteurisation. Nevertheless, the DPPH assay showed highest AOX in MTP-sample (1026.16 \pm 6.93$)$. There were some differences in value between both DPPH and FRAP for all samples. This was due to the difference in method and principle of measure between these two assays. When the different methods were compared, FRAP assay showed smaller values than DPPH due to a difference in measurement principle. The FRAP assay is a measure of the compounds' presence with reducing power in the juice while DPPH is a measure of the compound's presence with radical scavenging capacity (Sethi et al., 2020). Yet, the values obtained from FRAP assay were in good correlation with those from DPPH assay results at the $90 \%$ confidence level $(p<0.10)$ and $r=0.626$. This good correlation coefficient suggests that the antioxidant compounds showed increase in reducing power and radical scavenging capacity after the thermal pasteurisation process. As discussed by Farahmand et al. (2017) and Benjamin and Gamrasni (2020), the increasing level of AOX activity in pomegranate juice was attributed to the rise in TPC which include all flavonoid, anthocyanin and non-flavonoid phenolic compound. In this study, the level of AOX (based on FRAP and DPPH) were positively correlated with TPC suggesting that they contributed moderately to the AOX activity of samples.

\section{Conclusion}

MTP-treatment $\left(80^{\circ} \mathrm{C}, \quad 30 \mathrm{~s}\right)$ of reconstituted pomegranate juice as prepared from the concentrate, was effectively able to inactivate microbial growth equally to HTP-treatment $\left(95^{\circ} \mathrm{C}, 30 \mathrm{~s}\right)$. Beneficially, MTP required almost half pasteurisation-time as compared to HTP and hence, this suggests that high energy-saving can be obtained with MTP while complying the food safety requirement. No significant difference was found in term of change in $\mathrm{pH}$, total soluble solids and titratable acidity between MTP and HTP-treated juice. As for colour, MTP showed significantly higher CIE $a$ and lower CIE $L$, which implied more intensity in red colour but less darkness. Interestingly, HTP shows higher content of phenolic compound, anthocyanin and antioxidant activity based on FRAP assay than MTP, validating other studies with a different type of juices that found a similar rise in bioactive compounds after heating at high temperature due to further disruption in the cell membrane that releases membrane-bound phenols. Importantly, both MTP and HTP showed higher antioxidant capacity as compared to unpasteurised juice indicating an increase in reducing power and radical scavenging capacity. Overall, from this study MTP $\left(80^{\circ} \mathrm{C}, 30 \mathrm{~s}\right)$ can be an alternative condition for industries to pasteurise at a lower temperature with less time, energy and cost. Yet, measurement during storage need to be taken to prevent the possible microbial growth in MTP-treated juices such as refrigerated storage. On the other hand, HTP $\left(95^{\circ} \mathrm{C}\right.$, $30 \mathrm{~s})$ did not show detrimental effect on the phenol, anthocyanin and antioxidant activity of the RPJ, while in fact, has increased their values. 


\section{Acknowledgement}

The authors would like to acknowledge the financial support provided by Universiti Putra Malaysia (GPIPM/2019/9677900) under research grants.

\section{References}

Alighourchi, H.R., Barzegar, M., Sahari, M.A. and Abbasi, S. (2013). Effect of sonication on anthocyanins, total phenolic content, and antioxidant capacity of pomegranate juices. International Food Research Journal, 20(4), 1703-1709.

Andersson, K., Jensinger, P., Svensson, B. and Lanzingh, C. (2016). Juice pasteurization - Can we do better? Tetra Pak White Paper. Retrieved on $21^{\text {st }}$ January 2020 from Tetra Pak website: www.tetrapak.com

Batra, N.G., Sharma, A. and Agarwal, N. (2018). Evaluation of microbiological criteria and quality of packed fruit juices. International Food Research Journal, 25(2), 458-461.

Benjamin, O. and Gamrasni, D. (2020). Microbial, nutritional, and organoleptic quality of pomegranate juice following high-pressure homogenization and low-temperature pasteurization. Journal of Food Science, 85(3), 592-599. https:// doi.org/10.1111/1750-3841.15032

Boggia, R., Casolino, M.C., Hysenaj, V., Oliveri, P. and Zunin, P. (2013). A screening method based on UVVisible spectroscopy and multivariate analysis to assess addition of filler juices and water to pomegranate juices. Food Chemistry, 140(4), 735741. https://doi.org/10.1016/j.foodchem.2012.11.020

Cam, M., Hisil, Y. and Durmaz, G. (2009). Characterisation of pomegranate juices from ten cultivars grown in Turkey. International Journal of Food Properties, 12(2), 388-395. https:// doi.org/10.1080/10942910701813917

Colantuono, A., Vitaglione, P., Manzo, N., Blaiotta, G., Montefusco, I., Marrazzo, A. and Romano, R. (2018). Evaluation of microfiltration and heat treatment on the microbiological characteristics, phenolic composition and volatile compound profile of pomegranate (Punica granatum L.) juice. Journal of the Science of Food and Agriculture, 98(9), 33243332. https://doi.org/10.1002/jsfa.8836

Davarc1, A., Kadiroğlu, P., Diblan, S., Selli, S. and Kelebek, H. (2019). Influence of processing steps on phenolic composition of clarified and unclarified pomegranate juices as characterized by LC-DADESI-MS/MS. Journal of Food Processing and Preservation, 43(8), 14018. https://doi.org/10.1111/ jfpp. 14018

FAO/WHO Food Standards. (2005). Codex general standard for fruit juices and nectars (CODEX STAN 247-2005). FAO:Rome

Farahmand, M., Golmakani, M.T., Mesbahi, G. and Farahnaky, A. (2017). Investigating the effects of large-scale processing on phytochemicals and antioxidant activity of pomegranate juice. Journal of Food Processing and Preservation, 41(2), e12792. https://doi.org/10.1111/jfpp.12792

Kaavya, R., Pandiselvam, R., Kothakota, A., Priya, E.B. and Prasath, V.A. (2019). Sugarcane juice preservation: a critical review of the state of the art and way forward. Sugar Tech, 21(1), 9-19. https:// doi.org/10.1007/s12355-018-0622-2

Karimi, M., Sadeghi, R. and Kokini, J. (2017). Pomegranate as a promising opportunity in medicine and nanotechnology. Trends in Food Science and Technology, 69(Part A), 59-73. https:// doi.org/10.1016/j.tifs.2017.08.019

Kechero, F.K., Baye, K., Tefera, A.T. and Tessema, T.S. (2019). Bacteriological quality of commonly consumed fruit juices and vegetable salads sold in some fruit juice houses in Addis Ababa, Ethiopia. Journal of Food Safety, 39(1), e12563. https:// doi.org/10.1111/jfs.12563

Mayuoni Kirshenbaum, L., Benjamin, O. and Porat, R. (2016). Sensory and nutritional attributes of pomegranate juices extracted from separated arils and pressed whole fruits. Journal of the Science of Food and Agriculture, 96(4), 1313-1318. https:// doi.org/10.1002/jsfa. 7224

Mena, P., Vegara, S., Martí, N., García-Viguera, C., Saura, D. and Valero, M. (2013). Changes on indigenous microbiota, colour, bioactive compounds and antioxidant activity of pasteurised pomegranate juice. Food Chemistry, 141(3), 2122-2129. https:// doi.org/10.1016/j.foodchem.2013.04.118

Minatel, I.O., Borges, C.V., Ferreira, M.I., Gomez, H.A.G., Chen, C.Y.O. and Lima, G.P.P. (2017). Phenolic compounds: Functional properties, impact of processing and bioavailability. In SotoHernandez, M. (Ed.) Phenolic Compounds Biological Activity. InTech Open E-book. https:// doi.org/10.5772/66368

Murillo, M.A., Rodríguez-Pulido, F.J., Heredia, F.J., Melgosa, M., Pacheco, J., Vargas, R. and Gutiérrez, D. (2019). Colour evolution during a coating process of pharmaceutical tablet cores by random spraying. Colour Research \& Application, 44(2), 160-167. https://doi.org/10.1002/col.22332

Rinaldi, M., Caligiani, A., Borgese, R., Palla, G., Barbanti, D. and Massini, R. (2013). The effect of fruit processing and enzymatic treatments on 
pomegranate juice composition, antioxidant activity and polyphenols content. LWT-Food Science and Technology, 53(1), 355-359. https://doi.org/10.1016/ j.lwt.2013.02.015

Sethi, S., Joshi, A., Arora, B., Bhowmik, A., Sharma, R.R. and Kumar, P. (2020). Significance of FRAP, $\mathrm{DPPH}$, and CUPRAC assays for antioxidant activity determination in apple fruit extracts. European Food Research and Technology, 246, 591-598. https:// doi.org/10.1007/s00217-020-03432-z

Sharma, K., Ko, E.Y., Assefa, A.D., Ha, S., Nile, S.H., Lee, E.T. and Park, S.W. (2015). Temperaturedependent studies on the total phenolics, flavonoids, antioxidant activities, and sugar content in six onion varieties. Journal of Food and Drug Analysis, 23(2), 243-252. https://doi.org/10.1016/j.jfda.2014.10.005

Vegara, S., Martí, N., Mena, P., Saura, D. and Valero, M. (2013). Effect of pasteurization process and storage on colour and shelf-life of pomegranate juices. LWT-Food Science and Technology, 54(2), 592-596. https://doi.org/10.1016/j.lwt.2013.06.022

Yahia, E.M. (Ed.). (2017). Fruit and Vegetable Phytochemicals: Chemistry and Human Health, Vol. 2. John Wiley and Sons. https:// doi.org/10.1002/9781119158042

Zaouay, F., Mena, P., Garcia-Viguera, C. and Mars, M. (2012). Antioxidant activity and physico-chemical properties of Tunisian grown pomegranate (Punica granatum L.) cultivars. Industrial Crops and Products, 40, 81-89. https://doi.org/10.1016/ j.indcrop.2012.02.045 